\title{
A INFLUÊNCIA DA TRADIÇÃo SEMÂNTICA ANALÍTICA NA FILOSOFIA DE FREGE
}

\author{
Eduardo Antonio Pitt ${ }^{1}$ \\ Universidade de São Paulo (USP) \\ Universidade Federal do Acre (UFAC) \\ https://orcid.org/0000-0002-0728-3758 \\ E-mail: epitt26@yahoo.com.br
}

\section{RESUMO:}

O objetivo desse artigo é tentar esclarecer as origens e a importância filosófica do conceito de validade lógica objetiva no pensamento de Frege. Nosso argumento tentará localizar a filosofia de Frege dentro de uma tradição semântica analítica que surge no século XIX pelo pensamento de Bolzano e Lotze e que também se caracteriza pelo antinaturalismo, antipsicologismo e pela crença em uma objetividade a priori como característica de unidades logicamente válidas, mas não reais. $\mathrm{O}$ artigo irá identificar pontos em comum entre a filosofia desses três pensadores, mas, principalmente, queremos buscar nas filosofias de Bolzano e Lotze as raízes para entendermos a distinção entre os três reinos e o semanticismo platônico presentes na filosofia de Frege.

PALAVRAS-CHAVE: Semântica; Objetividade; Antipsicologismo.

\section{THE INFLUENCE OF ANALYTICAL SEMANTIC TRADITION IN FREGE'S PHILOSOPHY}

\begin{abstract}
:
The purpose of this article is to try to clarify the origins and philosophical importance of the concept of objective logical validity in Frege's thinking. Our argument will try to locate Frege's philosophy within an analytic semantic tradition that arises in the nineteenth century through the thinking of Bolzano and Lotze and which is also characterized by antinaturalism, antipsychologism and by the belief in an a priori objectivity as a characteristic of logically valid units, but not real. The article will identify common points between the philosophy of these three thinkers, but above all, we want to seek in the philosophies of Bolzano and Lotze the roots to understand the distinction between the three kingdoms and the Platonic semanticism present in Frege's philosophy.
\end{abstract}

KEYWORDS: Semantics; Objectivity; Antipsychologism.

\footnotetext{
${ }^{1}$ Doutorando em Filosofia na Universidade de São Paulo (USP), São Paulo - SP, Brasil. Professor de Filosofia da Universidade Federal do Acre (UFAC), Rio Branco - AC, Brasil.

PITT, Eduardo Antonio. A influência da tradição semântica analítica na filosofia de Frege. Griot : Revista de Filosofia, Amargosa - BA, v.18, n.2, p.325-337, dezembro, 2018. 


\section{Introdução}

Friedrich Ludwig Gottlob Frege (1848-1925) foi um matemático e filósofo alemão que lecionou na Universidade de Jena durante quarenta e quatro anos. Frege é reconhecido academicamente como um dos maiores lógicos de todos os tempos, podendo ser considerado como um dos precursores da filosofia analítica e o criador da lógica formal contemporânea. Contudo, ainda não há consenso a respeito de quais eram os fundamentos gerais do seu pensamento porque não temos em seus textos referências explícitas a filósofos que lhe antecederam e que influenciaram o seu pensamento. O que sabemos é que Frege fez parte do grupo de filósofos que se levantaram contra o naturalismo científico reinante no cenário acadêmico e científico da Europa de 1830 a 1870.

Nosso interesse é principalmente na noção de sentido das expressões linguísticas, aquilo que Frege denominou, no primeiro momento, de conteúdo judicável e, posteriormente, de Pensamento. Ao longo do artigo iremos apresentar as características dessas noções intensionais que justificam a necessidade da distinção entre os três reinos e a presença de um semanticismo platônico no pensamento de Frege, isto é, um projeto semântico muito amplo, de inspiração platônica, que perpassa diversas filosofias do final do século XIX. Nosso objetivo central é basicamente tentar mapear qual é a origem da tradição semântica analítica no séc. XIX e o quanto essa tradição influenciou Frege. Nossa hipótese é que localizando Frege no interior desta tradição temos um cenário que nos ajuda a entender os fundamentos filosóficos gerais do seu pensamento, principalmente o conceito de validade lógica objetiva.

\section{O surgimento da tradição semântica analítica}

Conforme Sluga ${ }^{2}$ (1980, p. 9-10), o naturalismo científico ganhou força na Alemanha contra uma tradição filosófica idealista que começou com Leibniz e terminaria com a morte de Hegel em 1831. Os naturalistas entendiam que com o avanço das ciências naturais e as mudanças em termos industriais no contexto político social da Europa o correto tratamento e explicação da vida humana deveriam ser pautados em termos naturalistas e materialistas. Por conta disso, nesse período a relevância da Filosofia foi questionada e os filósofos desacreditados foram colocados à margem do centro das discussões.

A restauração da relevância da Filosofia na Europa a partir de 1870 foi possível devido uma mudança no método filosófico. Os filósofos entenderam que era preciso mudar o foco da investigação filosófica para adequá-la aos avanços da biologia, da fisiologia e da psicologia. Segundo Beiser, "essas novas ciências fizeram a vida e a mente parecerem uma parte normal da natureza, sendo determinada e regulada por leis mecânicas e químicas quanto à própria matéria" (BEISER, 2013, p. 128). Nesse contexto onde a filosofia resistia contra as forças intelectuais do

\footnotetext{
${ }^{2}$ Sluga $(1980$, p. 17) destaca que o naturalismo científico emerge da crítica de Feuerbach ao sistema hegeliano como o paradigma de especulação metafísica e desenvolve-se na geração seguinte de naturalistas com Karl Vogt, Jakob Moleschott, Ludwig Büchner e Heinrich Czolbe que, não por coincidência, eram todos fisiologistas e basearam o naturalismo sobre os resultados das ciências empíricas.
}

PITT, Eduardo Antonio. A influência da tradição semântica analítica na filosofia de Frege. Griot : Revista de Filosofia, Amargosa - BA, v.18, n.2, p.325-337, dezembro, 2018. 
naturalismo, do materialismo e do positivismo, que formavam o alicerce do novo mundo científico e tecnológico, alguns filósofos entenderam "que sua tarefa era a investigação da estrutura lógica da matemática, ciência e linguagem. A Filosofia era possível no mundo contemporâneo como lógica formal" (SLUGA, 1980, p. 10).

Com o avançar do declínio do naturalismo científico e com o novo modus operandi de filósofos interessados nas ciências formais, construiu-se um cenário propício a um retorno à filosofia de Kant (1724-1804) ${ }^{3}$. Entre os adeptos da filosofia kantiana, um grupo de filósofos se enveredou na análise do conhecimento matemático, o que acabou originando uma tradição semântica analítica que adotou o a priorismo kantiano, mas rejeitou a intuição pura na fundamentação da matemática. Como diz Coffa,

a tradição semântica pode ser definida por seu problema, seu inimigo, seu objetivo e sua estratégia. O seu problema foi o a priori; seu inimigo a intuição pura de Kant; seu propósito, desenvolver uma concepção do $a$ priori em que a intuição pura não desempenha nenhum papel; sua estratégia, basear aquela teoria sobre o desenvolvimento da semântica. (COFFA, 1991, p. 22).

Bernard Placidus Johann Nepomuk Bolzano (1781-1848) teria sido o pioneiro dessa tradição semântica analítica ${ }^{4}$. A obra de Bolzano inseria-se no projeto mais amplo de aritmetização do cálculo, isto é, da redução das noções básicas do cálculo a noções aritméticas simples, tendo como objetivo último a eliminação da intuição pura dos juízos sintéticos a priori. De acordo com Coffa, "no campo da matemática, isto assumiu a forma de persistentemente excluir as ideias espaciotemporais de assuntos diferentes da geometria e continuamente questionar o valor de qualquer tipo de intuição na matemática" (COFFA, 1991, p. 29). É importante destacar que Frege também tinha pretensões fundacionalistas para a aritmética e, do mesmo modo que Bolzano, não concordava com Kant em relação ao papel da intuição pura nos juízos sintéticos a priori das demonstrações aritméticas.

Além disso, interessa-nos principalmente ressaltar a teoria semântica e as "entidades em si" de Bolzano apresentada no livro "Teoria da Ciência" de 1837. Para Niel (2014, p. 107), "essas unidades ideais de sentido "em si" são independentes da ontologia e da lógica e constituem uma ordem de "realidade" semelhante à que Platão ${ }^{5}$ atribuiu a seu topos ouranós". Segundo Niel (2013, p. 944), tais "entidades em si" seriam unidades semânticas a priori e foram chamadas por Bolzano de: "representações em si", "proposições em si" e "verdades em si". Bolzano queria fundamentar a ciência e a lógica em verdades gerais e se contrapondo à explicação

\footnotetext{
3 Segundo Sluga (1980, p. 36), a expressão "Back to Kant" foi usada pela primeira vez por Otto Liebmann em 1865 no livro "Kant und die Epigonen".

${ }^{4}$ Coffa (1991, p. 1), "no interior do campo da epistemologia podemos discernir três correntes principais de pensamento no séc. XIX: positivismo, kantianismo, e o que eu proponho chamar de tradição semântica". Coffa afirma que Bolzano teria sido o primeiro representante dessa tradição semântica analítica (1991, p. 21-22). Niel (2013, p. 940), "a influência de Bolzano pode ser rastreada não só na fenomenologia, mas também na primeira filosofia analítica". González Porta (2002, p. 252), “em Bolzano se encontra o início claro do antipsicologismo e, eventualmente, do próprio "semantic turn", (...)".

5 González Porta (2004, p. 109) afirma que o movimento conhecido como platonismo no séc. XIX "afirma a existência "em si" (isto é, independente da subjetividade) de objetos e estruturas lógicas não menos que a nossa capacidade de conhecê-las".
}

PITT, Eduardo Antonio. A influência da tradição semântica analítica na filosofia de Frege. Griot : Revista de Filosofia, Amargosa - BA, v.18, n.2, p.325-337, dezembro, 2018. 
naturalista e psicologista considerou essas "entidades em si" com autossubsistência independente da ordem do real, do linguístico e do psicológico. Ao mesmo tempo, tais "entidades em si" encontram contraparte no plano subjetivo real, ou seja, respectivamente, "representações subjetivas", "proposições pensadas" e "verdades conhecidas".

Isto ficará mais claro se recorrermos ao exemplo da noção de representação. Conforme Coffa, para Bolzano, “(...) cada unidade gramatical significativa está associada a uma série de representações subjetivas, mas com apenas uma representação objetiva, (...)" (COFFA, 1991, p. 30). A diferença entre a representação em si objetiva e a representação subjetiva é que "as representações subjetivas que surgem nas mentes dos meus leitores ao olhar a próxima palavra - nada - podem ser todas aparentemente iguais, mas, no entanto, existem muitas delas. A representação objetiva que esta palavra significa é, por outro lado, única" (BOLZANO, 1973, p. 79). Por isso, há na teoria de Bolzano uma diferença fundamental entre esses dois tipos de representação. A "representação subjetiva é algo real - no momento particular em que está presente, tem uma existência real na mente do sujeito para quem está presente", produzindo toda sorte de efeitos (BOLZANO, 1973, p. 78). A representação objetiva, por sua vez, é,

\begin{abstract}
algo que não deve ser procurado no âmbito da realidade, algo que compõe o material direto e imediato da representação subjetiva. Esta representação objetiva não requer nenhum sujeito para quem esteja presente, mas teria Ser - não certamente enquanto algo existente, mas, de qualquer modo, como um Algo determinado - mesmo que nenhum ser pensante possa apreendê-lo. E não se multiplica quando um ou dois ou três ou mais seres pensam nisso, pois a representação subjetiva relacionada a ele existe em número plural. Daí, o título objetivo. (BOLZANO, 1973, p. 78).
\end{abstract}

Outro filósofo de destaque nesse contexto, que foi professor ${ }^{6}$ de Frege e o influenciou fortemente, é Rudolf Hermann Lotze (1817-1881), pois exerceu papel importante de resistência da tradição filosófica alemã contra o avanço do naturalismo científico. Lotze se colocou contrário às explicações naturalistas e materialistas da fisiologia e da biologia e criticou a explicação naturalista da psicologia de reduzir o pensamento aos processos mentais, ideia central do psicologismo contra o qual Frege se manifestou de forma decisiva em diversas passagens.

Conforme a descrição de Beiser, quanto mais o naturalismo científico avançava em suas explicações "menos espaço parecia existir para o valor no universo, isto é, para o significado, propósito, liberdade, responsabilidade e beleza. A filosofia de Lotze surgiu (...), para encontrar algum lugar para o valor em um mundo naturalista" (BEISER, 2013, p. 128). Sendo assim, a filosofia de Lotze pode ser vista como uma tentativa de conciliar o valor e a ciência, o ideal com o real, e Lotze parecia ter as qualidades para tal empreendimento porque possuía conhecimentos tanto nas áreas da medicina, psicologia e fisiologia, quanto defendia uma visão de

\footnotetext{
${ }^{6}$ Segundo Alcoforado (2009, p. 10), Frege quando esteve em Göttingen no período de 1871 a 1873 teria entrado em contato com Lotze que foi o seu professor de Filosofia da Religião.
} 
mundo orgânica segundo a qual a natureza forma uma unidade viva intencional e que o real é apenas uma manifestação do ideal.

Por intermédio de livros como "Lógica", um longo tratado em dois volumes publicado em 1874, Lotze teria exercido forte influência em vários filósofos da segunda metade do século XIX, incluindo Frege. Nas palavras de Sluga (1984), a "Lógica" de Lotze teria despertado o interesse de Frege pela lógica, uma vez que, a formação técnica de Frege em Jena e em Göttingen era em matemática pura e ciências, fato que transparece no tratamento marginal de questões filosóficas tanto na sua dissertação doutoral "Sobre uma representação geométrica de figuras imaginárias no Plano" de 1873 quanto na sua tese de docência "Métodos de cálculo baseados sobre uma extensão do conceito de Grandeza" de 1874. De qualquer forma, ainda parafraseando Sluga (1984), podemos considerar que a "Lógica" de Lotze influenciou Frege no antipsicologismo, na caracterização de conceitos como funções, na terminologia de ideia e conteúdo, na crença de que as proposições da aritmética são fundamentadas em leis lógicas gerais sem apelo a intuição pura de Kant e na reformulação do platonismo em uma teoria livre de ontologia.

Sem dúvida, todos esses elementos acima estão presentes em certa medida no pensamento de Frege, contudo, queremos focar na distinção que Lotze faz entre realidade e validade. Como destaca Beiser, "Lotze fez uma distinção simples, mas seminal entre os domínios de validade e existência, verdade e realidade" (BEISER, 2013, p. 129). Tais distinções têm origem na sua interpretação da teoria das Ideias de Platão contida no $\S 318$ de sua "Lógica". Lotze defende que Platão estaria defendendo a validade ou a objetividade das Ideias em termos epistemológicos e não ontológicos. Segundo Lotze,

\begin{abstract}
enquanto Platão, ao descrever assim as Ideias, se assegura de sua validade independente, ele forneceu, ao mesmo tempo, abundantes razões contra a confusão entre a validade que decorre daí e a Existência completamente distinta que só poderia ser atribuída a uma coisa durável. Quando ele coloca o lar das Ideias em um mundo super-celestial, um mundo de inteligência pura [noetòs, hyperouránios topos], quando, ainda com mais ênfase, ele expressamente os descreve como não tendo habitação local, essa linguagem deixa bem claro a qualquer um que entenda a mentalidade da Antiguidade Grega, que tais Ideias não pertencem ao que chamamos de mundo real. Para o grego, o que não está no espaço não existe de maneira alguma, e quando Platão dá às Ideias uma morada que não está no espaço, ele não está tentando hipostasiar o que chamamos sua mera validade em qualquer tipo de existência real, mas, pelo contrário, está claramente procurando se proteger por antecipação contra qualquer tentativa desse tipo. (LOTZE, 1884, p. 443).
\end{abstract}

Nos termos colocados acima, o conceito de "validade" de Lotze é uma tentativa de esclarecer a natureza lógica de unidades objetivamente válidas, ou seja, não devemos interpretá-las como representações mentais e nem com existência real porque "ser válido" não significa Ser. O conceito de Ser caberia apenas às coisas reais, no sentido de existir causalmente no espaço e no tempo, ao passo que objetividade seria distinta de realidade porque os conteúdos objetivamente válidos que se encontram nesta ordem ideal a priori não estão no espaço e no tempo, nem mantêm relações causais entre si. Para Beiser, "foi esse domínio platônico de validade 
(...) que provou ser uma descoberta intoxicante para a nova geração. Esta foi a fonte da qual (...) Frege beberia poderosamente. Um novo e mais sofisticado platonismo havia nascido" (BEISER, 2013, p. 130).

Segundo Gottfried Gabriel, Lotze teria feito "o reencontro da filosofia platônica e kantiana em uma posição epistemológica que, de fato, poderia ser chamada de platonismo transcendental" (GABRIEL, 2002, p. 41). Assim, a epistemologia por trás do conceito de "validade" de Lotze é que, kantianamente falando, a percepção sensível é necessária, mas não suficiente para fundamentar o nosso conhecimento. Lotze e vários neokantianos admitiam a necessidade de aceitar verdades a priori que são a base do nosso conhecimento empírico. Como Platão, Lotze assume o pressuposto que nosso conhecimento a priori de elementos objetivos não espaciais e não temporais é fundamental para o nosso conhecimento das coisas que estão no espaço e no tempo em eterna mutação.

Sendo assim, temos informações relevantes que corroboram a visão de que Bolzano e Lotze foram filósofos fundamentais para o surgimento da tradição semântica analítica da qual influenciou a formação do pensamento de Frege. $O$ elo entre esses três autores no interior dessa tradição semântica analítica seria a rejeição da intuição pura de Kant como fundamento das proposições aritméticas, a postulação de uma objetividade a priori, fora do espaço e do tempo, não real, mas logicamente válida e independente dos seres humanos e o posicionamento antipsicologista consequência epistemológica da crença nas entidades objetivas $a$ priori contra o reducionismo naturalista e psicologista. Esse, que preferimos chamar de "o reino das objetividades", nos parece ser uma peça importante para entendermos o semanticismo platônico presente na filosofia de Frege porque este, no artigo "O Pensamento" de 1918, apresenta uma separação entre três reinos: o reino da subjetividade (nossos estados mentais), o reino da efetividade (objetos espaço temporais ligados por cadeias causais) e o reino da objetividade (entidades objetivamente válidas como Pensamentos, fatos, os sentidos dos componentes dos Pensamentos, valores de verdade, números, conceitos, funções, relações).

\section{O semanticismo platônico na semântica lógica de Frege}

A partir dessa tentativa de mapear o surgimento da tradição semântica analítica da qual acreditamos que Frege faz parte, iremos agora localizar na semântica de Frege onde se encontram as influências desta tradição no que diz respeito à noção de validade lógica objetiva. Estamos cientes de que estamos entrando no nível mais profundo do pensamento de Frege e de que estamos lidando com questões difíceis de serem respondidas se levarmos em conta apenas os textos deste autor. Por isso, justifica-se o nosso olhar para trás tentando localizar Frege em um contexto filosófico mais amplo que ajude a explicar as características filosóficas gerais da sua semântica lógica. Vamos analisar o percurso do desenvolvimento da semântica de Frege em duas fases distintas, a primeira fase perpassa o período de 1879 a 1890 e a segunda fase, a fase madura, o período de 1891 a 1925.

Podemos considerar que o principal objetivo do trabalho de Frege foi demonstrar que a matemática é uma derivação da lógica. Diante a necessidade de rigor e precisão nas provas dos teoremas da aritmética, Frege abdicou da linguagem 
natural e apresentou no livro "Conceitografia: uma linguagem formular do pensamento puro decalcada sobre a aritmética" de 1879 uma linguagem lógica que garantisse as corretas expressões e relações entre os conteúdos judicáveis objetivos e, segundo, que assegurasse a verdade nas demonstrações das inferências matemáticas sem deixar lacunas e sem apelo à intuição kantiana.

Tal linguagem simbólica atendia aos propósitos fregianos da seguinte maneira: o método de condução de provas era axiomático e o uso de axiomas lógicos garantia a exclusão de qualquer apelo à intuição, pois a justificação verdadeira dos teoremas da aritmética dependia exclusivamente da verdade dos axiomas, das definições e das regras de inferência contidas no sistema. A linguagem lógica da "Conceitografia" continha além das regras sintáticas que davam conta do alfabeto da linguagem e formação das expressões da linguagem um conjunto de axiomas e regras de inferência que nos permitem derivar novas expressões.

Por isso, importa a nós mais a questão semântica dessa "linguagem formular do pensamento puro" do que sua tecnicalidade lógica. Interessa-nos a sua capacidade de expressar os conteúdos judicáveis objetivos e as relações entre eles, pois na "Conceitografia", afirma Frege, "desde que em um juízo eu considero apenas aquilo que influencia suas possíveis consequências. Tudo que é necessário para uma inferência correta será totalmente expressado, (...), nada será deixado à adivinhação" (FREGE, 1997, p. 54).

A semântica de Frege da fase entre 1879 a 1891, como diz Coffa (1991, p. 67), era uma semântica monista e suas noções básicas eram a de conteúdo judicável, conceito e objeto. É verdade que os termos "conceito" e "objeto" que aparecem em "Os fundamentos da Aritmética" não são vistas na "Conceitografia" porque nesta Frege usou os termos "função" e "argumento". Contudo, esse desencontro terminológico é explicado ao entendermos que a semântica de Frege evoluiu gradualmente até a sua forma madura que foi apresentada a partir de 1891 e não se trata de uma diferença que invalide a afirmação de Coffa acima.

Segundo Coffa (1991, p.79), uma semântica monista é aquela que a cada item gramatical se associa apenas uma entidade semântica e tal entidade semântica se encontra no mundo. Ao passo que uma semântica dualista é aquela que a cada item gramatical se associam duas entidades semânticas, uma é o que a sentença diz e a outra sobre o que se trata e esta estaria no mundo. Coffa irá associar as duas espécies de semântica às duas fases distintas de Frege. Concordamos com Coffa nesse ponto, porém, duvidamos que todas as entidades semânticas se encontrem no mundo, isto é, no reino das efetividades.

O nosso entendimento é que no período da primeira semântica de Frege, ou seja, de 1879 a 1890, a noção semântica mais importante é a de conteúdo judicável entendido enquanto algo distinto do juízo que é a asserção desse conteúdo objetivo. Esta unidade semântica seria o elemento intensional objetivo a priori da lógica de Frege e, portanto, o legítimo candidato a ser o portador da Verdade. Na filosofia de Frege teríamos acesso a esta unidade objetiva a priori somente pelo pensamento puro sem qualquer relação com o psicologismo e o empirismo uma vez que a idealidade do conteúdo judicável se caracteriza pela sua validade intersubjetiva, a mesma característica que encontramos em Bolzano e Lotze. Sendo assim, consideramos que na primeira semântica a distinção entre os três reinos já estava implícita, como pano 
de fundo, no pensamento de Frege e a noção de conteúdo judicável objetivo seria uma das unidades ideais do reino das objetividades.

$O$ ponto de partida para o desenvolvimento da semântica monista para a semântica dualista do período de 1891 a 1925 se deve à forma que Frege caracterizou a identidade entre conteúdos conceituais nos $\S \S 3$ e 8 da "Conceitografia", respectivamente nos casos dos juízos e dos sinais de objetos. Devido à caracterização dada por Frege, podemos considerar que a noção de conteúdo conceitual é híbrida porque no $\S 3$ da "Conceitografia" o critério de identidade leva em conta o conteúdo informacional dos juízos, mas no $\S 8$, o critério de identidade leva em conta o objeto nomeado ou designado. A origem do problema parece estar na consideração que Frege fez no $\S 8$ da "Conceitografia" que a identidade é uma relação entre os sinais dos objetos e não entre os objetos mesmos e, para tanto, apresentou o símbolo de identidade (三) que provocava uma bifurcação no significado dos símbolos fazendo com que não representassem os seus conteúdos, mas a si próprios.

Em decorrência disso gerou-se o problema de sentenças de identidade verdadeiras e informativas conhecido como o "Quebra-cabeça da Identidade". Segundo o que Frege diz na "Conceitografia", podemos substituir dois sinais de objetos com o mesmo conteúdo conceitual em uma sentença assertiva. Se os dois sinais de objetos têm o mesmo conteúdo conceitual, então a sentença resultante da troca não sofrerá alteração no seu conteúdo informacional, mas não é isso o que acontece. Isto ocorre assim, se $\alpha=\beta$ é uma identidade verdadeira, isto significa que $\alpha$ nomeia o mesmo objeto que $\beta$ e que ambos expressam o mesmo conteúdo conceitual. Sendo a identidade verdadeira, podemos substituir $\alpha$ por $\beta$ e chegaríamos a uma nova sentença de identidade do tipo $\alpha=\alpha$. Se da primeira identidade concluímos que $\alpha$ expressa o mesmo conteúdo conceitual que $\beta$, a substituição de $\alpha$ por $\beta$ na segunda identidade deveria preservar o mesmo conteúdo informacional entre as sentenças, mas é nítido que as duas sentenças expressam conteúdos informacionais diferentes.

Frege soluciona este problema após 1891 abandonando a noção de conteúdo conceitual e assumindo a distinção entre sentido e referência. No artigo "Sobre o Sentido e a Referência" de 1892 Frege retoma a discussão sobre a identidade: se a identidade é uma relação entre objetos, como explicar a diferença no conteúdo informacional de $a=a$ e $a=b$ sendo $a=b$ verdadeira e, por outro lado, se a identidade é uma relação entre os sinais de objetos, ela seria uma relação arbitrária que não expressa nenhum tipo de conhecimento? Colocado o problema Frege considera que na maioria dos casos nosso objetivo com a relação de identidade é expressar algum conhecimento e no caso das expressões $a=a$ e $a=b$ sendo $a=b$ verdadeira conclui que "a diferença entre os sinais corresponde uma diferença no modo de apresentação daquilo que é designado" (FREGE, 1997, p.152). No trecho a seguir, a distinção entre sentido e referência é apresentada,

é, pois, plausível pensar que exista unido a um sinal (nome, combinação de palavras, letra), além daquilo por ele designado, que pode ser chamado de sua referência, ainda o que eu gostaria de chamar de o sentido do sinal, onde está contido o modo de apresentação do objeto. Consequentemente, segundo nosso exemplo, a referência das expressões ponto de interseção de a $e$ b ponto de interseção de $b$ e $c$ seria a mesma, mas não os seus sentidos. (...). A referência de Estrela da Tarde e Estrela da Manhã seria a mesma,

PITT, Eduardo Antonio. A influência da tradição semântica analítica na filosofia de Frege. Griot : Revista de Filosofia, Amargosa - BA, v.18, n.2, p.325-337, dezembro, 2018. 
mas não o sentido. (FREGE, 1997, p. 152).

Parece não haver dúvidas de que Frege considera os símbolos linguísticos sinais, os objetos designados por eles a referência desses sinais e o modo com que designamos os objetos o sentido dos sinais. A distinção entre sentido e referência foi expandida também para as expressões conceituais e para os sinais de objetos. A distinção saturado/insaturado continua rigorosa, mas agora as entidades semânticas conceito e objeto são a referência das suas respectivas expressões intermediado pelos sentidos de cada expressão correspondente.

Para ilustrar a semântica dualista adotada por Frege a partir de 1891 vamos citar abaixo um esboço enviado por Frege em "Carta a Husserl" de 1891(FREGE, 1997, p. 149):

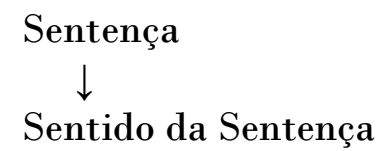

(Pensamento)<smiles>[AlH2]</smiles>

Referência da Sentença caindo

(Valor de Verdade) conceito

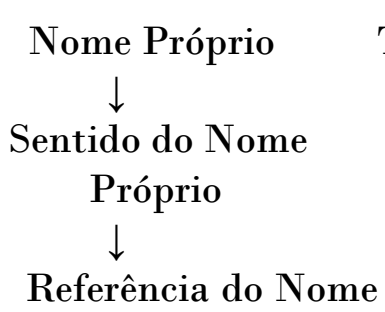

Próprio (Objeto)

\section{Termo Conceitual<smiles>[AlH2]</smiles> \\ Sentido do Termo}

Conceitual

Referência do Termo $\rightarrow$ objetos

Conceitual (Conceito) sobre o

Esse esboço é importante porque deixa claro o que Frege tinha em mente. Entre as entidades semânticas presentes na semântica madura de Frege a que mais notoriamente caracteriza o semanticismo platônico é a noção de Pensamento, entendido como o sentido de uma sentença assertiva. Frege, no artigo "Sobre o Sentido e a Referência", em nota de rodapé, esclarece que entende por Pensamento "não o ato subjetivo de pensar, mas seu conteúdo objetivo que pode ser a propriedade comum de muitos pensadores" (FREGE, 1997, p. 156). Em "Lógica" de 1897 e em "O Pensamento" de 1918 Frege apresenta as características dessas unidades semânticas, por exemplo, segue um trecho de "Lógica",

\footnotetext{
ao contrário das ideias, pensamentos não pertencem a mentes individuais (eles não são subjetivos), mas são independentes do nosso pensamento e confrontam cada um de nós do mesmo modo (objetivamente). Eles não são produtos do pensamento, mas somente são apreendidos pelo ato de pensar. Assim, eles são como corpos físicos. O que os distingue de corpos físicos é que eles são não espaciais e podemos talvez ir adiante e dizer que eles são essencialmente atemporais, ao menos na medida em que são imunes de tudo que pode afetar uma mudança na natureza intrínseca deles. Eles são como ideias em sendo não espaciais. (FREGE, 1979, p. 148).
}

É no artigo "O Pensamento" que Frege apresenta as distinções dos três reinos, "os pensamentos não são nem coisas do mundo exterior, nem ideias. É preciso admitir um terceiro domínio" (FREGE, 1997, p. 336). Esse terceiro domínio, que nós aqui estamos chamando de reino das objetividades, é totalmente distinto das esferas do psicológico (reino das subjetividades) e do empírico (reino das efetividades). 
Estabelecer a distinção rigorosa dos três reinos é, segundo Pardey (2012, p. 156), a principal tese de "O Pensamento" porque Frege quer mostrar que os Pensamentos sendo objetivos não são nem coisas sensorialmente perceptíveis e muito menos uma ideia subjetiva.

Frege afirma que os legítimos Pensamentos possuem um valor de verdade $a$ priori pelo motivo de não dependerem de nós os pensarmos. Como diz em "O Pensamento", "o pensamento que expressamos no teorema de Pitágoras é intemporalmente verdadeiro, verdadeiro independentemente do fato de que alguém o considere verdadeiro ou não" (FREGE, 1997, p. 337). No mesmo artigo encontramos,

pois o que chamei de pensamento está na mais estreita relação com a verdade. $O$ que reconheço como verdadeiro, julgo ser verdadeiro independentemente de reconhecê-lo como verdadeiro e independentemente de pensá-lo. $\mathrm{O}$ ser verdadeiro de um pensamento nada tem a ver com o fato de ser pensado. (FREGE, 1997, p. 343).

Frege, no trecho acima, coloca o Pensamento na mais íntima relação com a Verdade e dado a importância dessa noção para a lógica é preciso dizer algo mais sobre ela. Frege em "Lógica" (1979, pp. 128-129) e "O Pensamento" (1997, pp. 326327) apresenta argumentos similares para defender a tese de que a Verdade é indefinível e que a relação íntima entre o Pensamento e a Verdade pode ser explicada porque os Pensamentos são os únicos portadores da Verdade. Frege tinha uma noção de Verdade científica que é Absoluta, Perfeita e Independente ao passo que as outras teorias que tentam definir a Verdade pressupõem uma Verdade Relativa, Imperfeita e Dependente. Concordamos com Pardey (2012) que Frege nos argumentos de "Lógica" e "O Pensamento" parece deixar claro que a Verdade não admite qualquer tipo de correspondência, seja entre uma ideia e aquilo que ela representa, seja entre uma sentença e um fato. Uma vez que o portador da Verdade é o Pensamento sua relação com os objetos lógicos o Verdadeiro ou o Falso é uma relação necessária e não dependeria de correspondência empírica.

A questão ainda se torna mais interessante na medida em que seria impossível para Frege projetar uma relação de correspondência entre o Pensamento e o fato porque o que costumeiramente chamamos de "fatos" parece não ser a mesma coisa para Frege, pois este causa surpresa ao dizer que fatos não estão no reino das efetividades. Em "Lógica" Frege diz, "exemplos de pensamentos são leis da natureza, leis matemáticas e fatos históricos" (FREGE, 1979, p. 131). Em "O Pensamento" Frege declara, "um fato é um pensamento que é verdadeiro" (FREGE, 1997, p. 342), ou seja, fatos são um tipo de Pensamento, a saber, os Pensamentos verdadeiros, uma vez que, Pensamentos falsos não são fatos, mas continuam sendo Pensamentos. Nesse sentido, fatos estariam no reino das objetividades e não no reino das efetividades como os objetos concretos reais.

Sendo assim, parece coerente a interpretação de que a noção de validade lógica objetiva usada por Frege nasce da tradição semântica analítica cujas origens remetem a Bolzano e principalmente Lotze. Dado o antinaturalismo e o antipsicologismo desses três autores parece correto afirmar que o reino das objetividades deve ser interpretado menos ontologicamente do que 
epistemologicamente porque Bolzano, Lotze e Frege sustentam que o conhecimento oriundo dessas unidades objetivas é não empírico. Se Pensamentos fossem reais iríamos interagir com eles causalmente assim como fazemos com os objetos que se encontram no espaço e no tempo e como fazemos com nossas ideias subjetivas. Frege considerava que as leis lógicas eram leis universais, sendo analíticas a priori essas leis se aplicariam a tudo o que é pensável irrestritamente e, dessa forma, a lógica seria o fundamento básico de todo o conhecimento humano. Não por coincidência isto reflete o mesmo posicionamento encontrado em Bolzano e Lotze de que verdades $a$ priori fundamentam o nosso conhecimento empírico.

\section{Considerações finais}

Nossa reflexão foi sobre a respeito das similaridades entre as filosofias de Bolzano, Lotze e Frege com relação à postulação de um reino das objetividades onde se encontrariam unidades semânticas objetivas a priori que não são reais, mas são logicamente válidas. Podemos concluir que o a priorismo presente no pensamento de Frege é de fundamental importância para a sua lógica porque esta estaria comprometida com o conteúdo, a expressão e as relações dessas unidades válidas e objetivas. Esse a priorismo garantiu a separação da lógica das pretensões naturalistas e psicologistas, além de colocar as leis lógicas gerais em posição de primazia em relação às leis naturais. 


\section{Referências}

ALCOFORADO, P. Lógica e Filosofia da Linguagem: Gottlob Frege. Seleção, introdução, tradução e notas de Paulo Alcoforado. $2^{\text {a }}$ edição amp. e rev.. São Paulo: Editora da USP, 2009.

BEISER, Frederick C. Late German Idealism: Trendelenburg and Lotze. United Kingdom: Oxford University Press, 2013.

BOLZANO, Bernard. Theory of Science. Edited with an Introduction by Jan Berg. Translated from the German by Burnham Terrell. Boston - USA: D. Reidel Publishing Company, 1973.

COFFA, J. Alberto. The semantic tradition from Kant to Carnap: to the Vienna Station. Edited by Linda Wessels. Indiana - USA: Cambridge University Press, 1991. FREGE, Gottlob. Begriffsschrift: a formula language of pure thought modelled on that of arithmetic (Preface and Part I). In: BEANEY, Michael. The Frege Reader. Oxford - England: Blackwell Publishers, 1997, p. 47-78.

. Letter to Husserl. In: BEANEY, Michael. The Frege Reader. Oxford - England: Blackwell Publishers, 1997, p. 149-150.

On Sinn and Bedeutung. In: BEANEY, Michael. The Frege Reader. Oxford England: Blackwell Publishers, 1997, p. 151-171.

. Logic. In: HERMES, Hans; KAMBARTEL, Friedrich; KAULBACH, Friedrich.

Translate by Peter Long and Roger White. Gottlob Frege PosthumousWritings. Oxford - England: Basil Blackwell, 1979, p. 126-151.

- Thought. In: BEANEY, Michael. The Frege Reader. Oxford - England: Blackwell Publishers, 1997, p. 325-345.

GABRIEL, Gottfried. Frege, Lotze, and the Continental Roots of early Analytic Philosophy. In: RECK, Erich H.. From Frege to Wittgenstein: Perspectives on early Analytic Philosophy. England: Oxford University Press, 2002, p. 39-51.

GONZÁLEZ PORTA, Mario Ariel. Platonismo e Intencionalidade: a propósito de Bernard Bolzano I. Síntese, v. 29, n. 94, p. 251-275, 2002.

Platonismo e Intencionalidade: a propósito de Bernard Bolzano II. Síntese, v. 30, n. 96, p. 85-106, 2003.

Gottlob Frege: del Platonismo a la Fenomenología. Revista de Humanidades de Valparaíso, n. 4, p. 21-32, 2014.

A polêmica em torno ao Psicologismo de Bolzano a Heidegger. Síntese, v. 31, n. 99, p. 107-131, 2004.

LOTZE, R. Hermann. Logic. 2nd ed., Edited by Bernard Bosanquet. Oxford England: Clarendon Press, 1884.

NIEL, Luis I. Antipsicologismo y platonismo en el siglo XIX: Herbart, Bolzano y Lotze. Revista de Filosofia, v. 39, n. 1, p. 95-118, 2014.

Semántica y Ontología. Reflexiones em torno a la Wissenschaftslehre de Bolzano. Pensamiento, v. 69, n. 261, p. 939-962, 2013.

PARDEY, Ulrich. Frege on Absolute and Relative Truth: an introduction to the practice of interpreting philosophical texts. Edited by Michael Beaney. Germany: Palgrave Macmillan, 2012.

SLUGA, H. Hans. Gottlob Frege. Edited by Ted Honderichn. New York - USA: Routled \& Kegan Paul, 1980. (Series The Arguments of the Philosophers). 
Frege on the Indefinability of Truth. In: RECK, Erich H.. From Frege to Wittgenstein: Perspectives on early Analytic Philosophy. England: Oxford University Press, 2002, p. 75-95.

Frege: the early years. In: RORTY, R.; SCHNEEWIND, J. B.; SKINNER, Q.. Philosophy in History: essays on the historiography of philosophy. England: Cambridge University Press, 1984, p. 329-356.

Frege and the rise of analytic philosophy. Inquiry An Interdisciplinary Journal of Philosophy, v. 18, p. 471-487, 1975.

Autor(a) para correspondência: Eduardo Antonio Pitt, Universidade Federal do Acre, Centro de Filosofia e Ciências Humana, Rodovia BR 364, Km 04 - Distrito Industrial, CEP 69920-900 Rio Branco - AC, Brasil. epitt26@yahoo.com.br 